\title{
Direitos sociais e cidadania
}

\author{
Social rights and citizenship
}

\begin{abstract}
Alessandro Pinzani*
Universidade Federal de Santa Catarina, (UFSC), SC, Florianópolis, Brasil

\section{Resumo}

O presente texto tenta oferecer uma fundamentação dos direitos sociais quer a partir de uma perspectiva neoliberal, quer a partir de uma visão mais substantiva de cidadania. Ao mesmo tempo, contudo, será salientada a diferença entre as duas posições apresentadas e defendida a segunda. Na primeira parte será discutira a noção hayekiana de Grande Sociedade, que representa um avatar da ideia de sociedade característica da tradição liberal. Em seguida, se chegará a uma visão mais substantiva e robusta da sociedade organizada politicamente na forma-Estado e se mostrará a necessidade de políticas de inclusão, entendida não somente em sentido socioeconômico, mas também em sentido político e civil. A tese central é a de que a garantia de direitos sociais amplos é necessária quer para a estabilidade da sociedade, quer para legitimar as instituições de tal sociedade.
\end{abstract}

Palavras-chave: Direitos sociais. Cidadania. Hayek. Inclusão Social. 


\section{Abstract}

The present essay aims at offering a foundation of social rights both from a neoliberal perspective and from a more substantive view of citizenship. At the same time, though, it will highlight the difference between the two positions and defend the second one. In the first part, it will discuss Hayek's ideal of Great Society, which represents an avatar of the idea of society that characterizes the liberal tradition. Furthermore, it will present a more substantive view of society as a body politically organized in a State-form and it will show the necessity of policies aiming at inclusion, understood not only in socio-economic sense, but also in a political and civic sense. The main thesis is that guaranteeing social rights is necessary both for a society's stability and for the legitimacy of social institutions.

Keywords: Social rights. Citizenship. Hayek. Social inclusion.

\section{Introdução}

Neste texto gostaria primeiramente de oferecer uma fundamentação dos direitos sociais a partir de uma perspectiva neoliberal, para depois passar a uma fundamentação alternativa baseada numa visão mais substantiva de cidadania. Deve-se encontrar a razão desta dupla justificação na tentativa de mostrar a necessidade da garantia de direitos sociais, qualquer que seja a visão geral de sociedade que se defende. Ao mesmo tempo, pretendo salientar a diferença essencial entre as duas posições apresentadas e defender a segunda.

Partirei da noção hayekiana de Grande Sociedade, já que ela representa um avatar da ideia de sociedade característica da tradição contratualista e liberal, embora pessoalmente, eu a considere bastante inadequada como descrição do que realmente é uma sociedade. Em seguida, introduzirei argumentos que nos levarão a uma visão mais substantiva e robusta da sociedade organizada politicamente na forma-Estado. Ao fazer isso, pretendo mostrar a necessidade de políticas de inclusão. Entendo tal necessidade quer em sentido funcional, isso é, para garantir a subsistência do sistema social em questão, quer em sentido normativo, isto é, para legitimar tal sistema não somente aos 
olhos de seus membros, mas em uma ótica mais geral. Sempre neste contexto, entendo inclusão não somente em sentido socioeconômico, mas também em sentido político e civil. A tese à qual pretendo chegar é que a garantia de direitos sociais amplos é necessária quer para a estabilidade da sociedade, quer para legitimar as instituições de tal sociedade. Assim, políticas públicas que visem à garantia de direitos sociais são na realidade políticas de cidadania.

\section{$* * *$}

As polêmicas sobre programas de combate à pobreza como o Programa Bolsa Família demonstram que a existência de direitos sociais segue sendo objeto de contestação por setores relevantes da opinião pública brasileira. Tais setores não são numericamente relevantes, já que representam uma parcela minoritária da sociedade, mas são também os únicos cuja opinião é veiculada pela mídia nacional - que notoriamente não dá voz às camadas pobres da população. Até nos EUA, nos quais nenhum governo conseguiu, até agora, implementar um sistema de saúde pública em nível federal. Há, em geral, e com a única exceção das bandas mais libertárias e radicais do Partido Republicano e do Tea Party um consenso sobre a necessidade de medidas emergenciais para ajudar os cidadãos que se encontram em situação de pobreza extrema. O próprio Hayek, que foi o grande teórico do livre mercado e de sua ordem espontânea, bem como o grande crítico da ideia de justiça social, reconheceu a necessidade de políticas públicas que visem à inclusão no mercado dos indivíduos que circunstâncias históricas ou contingências econômicas privaram da capacidade de sair autonomamente da sua situação de exclusão socioeconômica. Ele chegou até a defender a introdução de uma renda mínima universal, colocando-se assim mais à esquerda dos liberais e neoliberais brasileiros (lembro, em parênteses, que em oito de janeiro de 2004 o Congresso aprovou a Lei $\mathrm{n}^{\circ}$ 10.835, que institui a Renda Básica de cidadania - lei que até agora não foi implementada). Vale a pena citar o seguinte trecho do terceiro livro de Direito, Legislação e Liberdade, já que oferece um ótimo ponto de partida para nossas reflexões. Cito Hayek (1985, p. 59): 
A garantia de uma renda mínima para todos, ou uma espécie de piso abaixo do qual ninguém precisa descer, mesmo quando incapaz de se sustentar por si mesmo, parece constituir não só uma proteção perfeitamente legítima contra um risco comum a todos, como também um elemento indispensável da Grande Sociedade, em que o indivíduo já não tem direitos sobre os membros do pequeno grupo onde nasceu. Um sistema que visa a incitar grande número de pessoas a abandonar a relativa segurança proporcionada pela condição de membro do pequeno grupo provavelmente logo geraria insatisfação e reação violenta quando seus primeiros beneficiários se vissem desamparados ao perder, não por culpa própria, sua capacidade de ganhar a vida.

Essas considerações são interessantes não somente por apontarem para uma possível justificativa da existência de direitos sociais a partir de uma perspectiva neoliberal contrária à ideia de justiça social, mas também por salientarem alguns aspectos que passam despercebidos no debate atual no Brasil. O primeiro é a função de integração social e civil de políticas públicas que ofereçam uma rede de proteção social mínima. $\mathrm{O}$ segundo diz respeito à questão da responsabilidade individual para a própria situação socioeconômica. Nesta fala, pretendo analisar particularmente o primeiro deles, mas farei também algumas rápidas considerações sobre o segundo.

Em certo sentido, a noção hayekiana de Grande Sociedade é uma elaboração da noção popperiana de Sociedade Aberta. Contrapõe-se ao grupo ou à formação tribal, ao pequeno grupo mencionado na citação que acabei de ler. Este é formado por indivíduos unidos por laços de sangue ou, mais genericamente, por relações essenciais fortes (cultura, língua, religião, etc.). A Grande Sociedade, pelo contrário, é tendencialmente aberta e qualquer indivíduo pode participar dela sem que se exija, que compartilhe com os demais membros vínculos culturais ou étnicos. É uma sociedade na qual as relações entre indivíduos são anônimas, já que são determinadas por mecanismos jurídicos igualitários (ninguém possui privilégios) e por mecanismos econômicos (por ex. os contratos de compra e venda). Nela os indivíduos são livres, uma vez que não dependem da vontade dos outros, como nas sociedades tradicionais (por ex. a sociedade feudal, na qual há senhores e servos). Contudo, apesar de garantir a seus membros o máximo de liberdade 
individual, ela não resulta no caos e na anarquia, uma vez que as relações que os membros estabelecem livremente entre si acabam resultando numa ordem espontânea (oposta à ideia de uma ordem não espontânea, imposta por uma autoridade superior como o Estado). Isso, contudo, não significa que Hayek rechace completamente a presença de uma autoridade superior e de qualquer tipo de planificação. $\mathrm{Na}$ Grande Sociedade há uma mistura de cosmos e taxis, ou seja, de ordem espontânea resultante da livre ação individual e de ordem resultante de uma planificação e de uma finalidade comum. O próprio mercado é um bom exemplo disso, uma vez que, necessita para funcionar, de regras jurídicas impostas eventualmente com a força, ou seja, necessita da ação de um governo, enquanto os resultados das transações econômicas no seu interior resultam numa ordem espontânea.

Aparecem nesta visão algumas feições características da tradição liberal. Os indivíduos são considerados como átomos isolados, dotados de uma liberdade que é, ao mesmo tempo, espontaneidade e arbítrio ilimitado. Os únicos limites legítimos de tal liberdade são aqueles autoimpostos ou livremente aceitos pelos próprios indivíduos, conforme a noção rousseauiana de autonomia. Os laços comunitários são vistos como limites externos, dos quais os indivíduos deveriam liberar-se para serem plenamente livres. A própria Grande Sociedade não é expressão de um grupo humano pré-constituído, mas inclui tendencialmente toda a humanidade. Não existe comunidade, nesta visão, mas somente indivíduos e a sociedade. Quando Margaret Thatcher afirmou que a sociedade não existe ("There is no such thing as society"), se referia à sociedade entendida como conjunto de relações comunitárias, de solidariedade, de lealdades locais etc., não à Grande Sociedade. A convicção de que as ações individuais levariam a uma ordem espontânea é evidentemente devedora da ideia da mão invisível de Adam Smith (1996). Deixarei de lado neste contexto a questão se tal convicção encontra respalde nas observações empíricas das ciências sociais ou se caracteriza antes como mera crença, pois isso não é relevante para nossos fins.

Ora, até a partir dessa visão de sociedade como mistura de ordem espontânea e de ordem planificada, na qual dominam as relações 
econômicas e, portanto, a racionalidade econômica da maximização dos úteis, é necessário garantir aos indivíduos uma proteção contra os possíveis resultados negativos do mercado. Lembro que para Hayek o mercado não é nem justo nem injusto, uma vez que cada situação econômica resulta de um conjunto de ações espontâneas praticamente incontáveis e, portanto, não reduzíveis à responsabilidade dos indivíduos. Por isso, ele rechaça a noção de justiça social. Ao mesmo tempo, isso significa que os indivíduos nunca são plenamente responsáveis por sua posição social e econômica. Até os indivíduos que se esforçam para obedecer aos sinais que o mercado envia e investem todas suas energias para obter sucesso nele, podem acabar fracassando por razões que não dependem deles. Por isso, Hayek fala em "risco comum a todos", contra o qual é necessário que o Estado construa uma rede de segurança. Hayek pensa especificamente em uma renda mínima universal, pois isso lhe parece ser a maneira melhor de salvaguardar a liberdade individual, uma vez que cada indivíduo fica livre para decidir como investir sua renda e, portanto, em decidir como gerir seus recursos e planejar sua vida. Em parênteses: Paradoxalmente, isso poderia levar a uma justificativa neoliberal de programas de transferência de renda como o PBF. ${ }^{1}$

Hayek introduz também um segundo argumento em prol da existência de uma rede de segurança social, que difere do primeiro pela sua natureza. Enquanto esse visa salvaguardar a liberdade individual contra o risco de exclusão do sistema socioeconômico e possui, portanto, um caráter normativo (a liberdade individual deve ser salvaguardada), o segundo argumento se preocupa com as possíveis consequências negativas da exclusão sobre a paz social e possui, portanto, um caráter mais funcional. A preocupação principal aqui é a de garantir estabilidade à sociedade e evitar "a insatisfação e a reação violenta" dos excluídos. Olhando a correspondência entre o altíssimo nível de desigualdade e de exclusão social, por um lado, e o igualmente altíssimo nível de violência na sociedade brasileira, pelo outro, parece razoável estabelecer uma relação causal entre os dois fenômenos, conforme

Não admira, portanto, que certa esquerda brasileira critique o PBF por ser presumidamente um programa neoliberal.

Rev. Filos., Aurora, Curitiba, v. 28, n. 43, p. 119-134, jan./abr. 2016 
a sugestão de Hayek, que aqui, contudo, segue uma longa tradição que vai de Rousseau a Hegel. Hegel, em particular, tinha chamado a atenção para a perda de "substância ética", de lealdade social e legal que, segundo ele, é consequência da exclusão social e da formação de uma plebe impossibilitada de inserir-se ou reinserir-se estavelmente no tecido conetivo da sociedade civil. Em outras palavras, como esperar que indivíduos que a própria sociedade acaba excluindo em consequência não do mau funcionamento dos mecanismos econômicos, mas justamente em consequência da maneira em que tais mecanismos agem normalmente, criando desemprego e desigualdade, como esperar que estes indivíduos sintam lealdade pelas instituições de tal sociedade e obedeçam a regras jurídicas que sancionam sua exclusão definitiva ao permitir a ação dos mecanismos citados?

Até agora fiz referência ao texto de Hayek, para mostrar como é possível fundamentar a existência de direitos sociais amplos (uma renda mínima universal) até a partir de uma perspectiva individualista que rechaça noções como as de justiça social e de solidariedade civil. Contudo, a partir de agora gostaria de apresentar uma posição alternativa, que tenha como ponto de partida não somente outra visão da sociedade e dos laços interpessoais que a mantêm unida, mas também da natureza da liberdade e dos direitos individuais.

O modelo alternativo ao modelo liberal puro de tipo hayekiano não é, necessariamente, um modelo comunitarista, no qual os direitos individuais correm o risco de passar em segundo plano frente os direitos do grupo ou da comunidade. É antes um modelo que insiste também nos direitos individuais, mas acrescenta aos tradicionais direitos civis e políticos, tão caros aos liberais, os direitos sociais.

Foi formulado em sua expressão talvez mais pura por Thomas Marshall em seu clássico texto de 1950 sobre Cidadania e classe social (MARSHALL, 1967). Esta obra é conhecida porque nela Marshall introduz a ideia de que haveria diferentes gerações de direitos: civis, políticos e sociais, que foram introduzidas em momentos diversos da história e que teriam acabado formando a moderna noção de cidadania que caracteriza a sociedade europeia contemporânea. Mas o argumento de Marshall não representa uma mera reconstrução histórica da 
maneira em que os direitos individuais foram se impondo na política e na legislação dos modernos estados europeus. Marshall apresenta uma verdadeira teoria da cidadania na qual as três gerações de direitos estão profundamente entrelaçadas. Em outras palavras, não está afirmando que os direitos mais antigos seriam os direitos mais fundamentais, enquanto as gerações sucessivas representariam tipos de direitos menos fundamentais e necessários, como defendem alguns autores liberais que negam justamente aos direitos sociais o caráter de direitos fundamentais. Pelo contrário, Marshall afirma que é somente através da garantia dos direitos sociais que os direitos civis e políticos passam a ser implementados de forma adequada, deixando de ser garantidos de maneira meramente formal. Em outras palavras, os direitos civis e políticos só podem ser desfrutados plenamente se seus portadores dispuserem das condições materiais necessárias para tanto.

Não discutirei aqui a teoria da cidadania de Marshall em seus pormenores, mas limitar-me-ei a salientar este ponto central: os direitos sociais não são meramente um acréscimo tardio aos direitos individuais fundamentais, mas são a condição para que os direitos previamente garantidos de maneira formal passem a ser desfrutados de maneira real. ${ }^{2}$

O processo que levou à garantia das diferentes gerações de direitos não foi, como se sabe, um processo pacífico, mas passou por inúmeras lutas, que vão das grandes revoluções modernas às lutas sindicais e operárias do final do século XIX e do século XX. Neste sentido, os direitos individuais são o fruto de uma conquista civilizatória, uma vez que liberam os indivíduos do arbítrio e da dominação dos seus governantes. No entanto, ao constituir as condições para o exercício daquilo que denominamos de cidadania, estes diferentes tipos de direitos apontam para uma dimensão que vai além da sua mera garantia.

Ao mesmo tempo em que os direitos abrem espaço de liberdade individual, o princípio da reciprocidade que funda a ideia mesma de direitos subjetivos pressupõe a existência de deveres para com a comunidade política de pertinência, ou seja, a existência de certa consciência

2 Em seguida retomarei observações elaboradas em LEÃO REGO e PINZANI 2013. 
de que a fruição e a demanda por direitos exigem obrigações, tanto para consigo mesmo, quanto para com a comunidade política maior, no caso, a nação. Ao menos, desde a Revolução Francesa a nação significa pertença a um ente coletivo que, antes das divisões de classes e outras partições existentes em seu interior, remete à existência de forças políticas e simbólicas unificantes, às forças centrípetas que vinculam as pessoas e àquele sentimento que existe em cada membro particular da comunidade política. Trata-se do pertencimento a um nós: nós os brasileiros, nós os italianos etc., sem o qual a garantia de direitos individuais não somente deixa os indivíduos isolados e atomizados, mas se torna até impossível, na ausência de uma percepção compartilhada da necessidade de que a comunidade política como um todo se encarregue de tal garantia.

Contudo, a existência desse ente coletivo completamente partido entre, por um lado, pobres e muito pobres e, por outro, ricos com forte cultura do privilégio, como na Europa dos séculos XVIII e XIX ou como no Brasil contemporâneo, dificilmente cria e fortalece laços de solidariedade e de pertinência comum. Ao contrário, a distância social que as assimetrias situacionais produzem em um povo desenvolve nele forças centrífugas, que criam separações e divisões ainda mais profundas no seu seio, fazendo dos habitantes de seu território estranhos que não se reconhecem em nenhum nível como iguais, a não ser no assimétrico dever de obedecer às leis comuns. Não devemos esquecer, como lembra sempre Habermas, que "[...] toda ordem jurídica é também expressão de uma forma de vida em particular, e não apenas o espelhamento do teor universal dos direitos fundamentais" (HABERMAS, 2002, p. 245).

Nesse contexto se acrescenta o risco de que a presença de lacerações internas à sociedade solape irreparavelmente suas estruturas democráticas. A ideia de um igual direito de participação política, que caracteriza nossas democracias, se fundamenta num princípio ético, a saber, o princípio do igual respeito: cada um possui os mesmos direitos que os outros no que diz respeito à participação na vida política de sua comunidade, porque cada um merece a mesma atenção e a mesma consideração (isto quer dizer: o que merece a mesma atenção e consideração são os indivíduos assim como seus interesses, suas preferências, 
suas necessidades etc.: $c f$. GALEOTTI, 2010). Contudo, esta conexão entre direitos de participação e respeito se perde por razões historicamente contingentes. Por exemplo, nos EUA depois da Guerra Civil os Afro-americanos obtiveram os mesmos direitos políticos da população branca, mas em muitos casos não gozavam dos mesmos direitos civis e não obtiveram o respeito dos cidadãos brancos. Torna-se útil aqui a distinção de Avishai Margalit (1996) entre sociedade decente e civilizada. A primeira seria uma sociedade na qual as instituições não humilham os membros, a segunda seria uma sociedade na qual os membros (em particular: grupos de indivíduos) não se humilham entre si. Neste sentido, poderíamos dizer que os EUA pós-Guerra Civil eram uma sociedade decente (pelo menos no caso dos estados que não negavam iguais direitos civis aos negros), mas não uma sociedade civilizada. $\mathrm{O}$ mesmo poder-se-ia dizer do Brasil depois da abolição da escravidão em 1888: à não-discriminação formal não correspondeu e, em grande parte, ainda não corresponde uma atitude de respeito por parte de uma parcela da população branca perante os ex-escravos e seus descendentes. No caso do Brasil, contudo, o racismo clássico pautado na discriminação com base na cor da pele (cuja presença, banalizada por muitos teóricos e por muitos brasileiros comuns, foi eficazmente demonstrada pelos estudos clássicos de Florestan Fernandes ${ }^{3}$ ) vem acompanhado de um verdadeiro classismo, que baseia a discriminação do Outro na sua pertença a uma classe social inferior.

Portanto, políticas sociais não devem ser comparadas a meros atos de caridade pública. Elas são antes instrumentos para promover autonomia individual e criar um senso de comunidade, em uma palavra: elas são instrumentos de cidadania, pois visam "proteger o status de uma pessoa como membro pleno da comunidade" (HARRIS, 1987, p. 30). Às vezes são justificadas com base na ideia de uma compensação para os indivíduos deixados às margens ou fora do sistema econômico de mercado, que, se o sistema fosse outro, se encontrariam em posição melhor. Ainda que aceitássemos a ideia neoliberal de que ninguém é responsável pessoalmente pelos desequilíbrios e pelas

\footnotetext{
0 estudo clássico de Fernandes é, naturalmente: FERNANDES, 1965.
} 
grandes diferenças de riqueza criadas pelo mercado, há uma responsabilidade coletiva da comunidade perante todos os seus membros, particularmente quando alguns entre eles são prejudicados pelo arranjo socioeconômico que permite a outros indivíduos acumular riquezas. Contudo, não é necessário recorrer a tais argumentos, bastante problemáticos, para justificar políticas sociais públicas. O argumento mais forte parece-nos ser o ligado à inclusão social dos indivíduos beneficiários destas políticas.

David Harris, no livro Justifying State Welfare (1987), escrito justamente para justificar a existência de um estado de bem-estar social, oferece a seguinte reflexão para fazer da satisfação das necessidades básicas uma condição fundamental para a cidadania:

Políticas sociais deveriam ser dirigidas para a garantia de um leque de opções sociais para os cidadãos de uma sociedade. As chances de vida relevantes são as exigidas para proteger o status dos indivíduos enquanto membros plenos da comunidade. A finalidade [de tais políticas] é a de oferecer oportunidades materiais para participar do modo de vida da sociedade. Isso implica que as necessidades sejam definidas como tudo o que for necessário para tal finalidade. Do ponto de vista das políticas sociais, um indivíduo se encontra 'necessitado' na medida em que lhe faltam os recursos para participar como membro pleno da sociedade no modo de vida desta última. (HARRIS, 1987, p. 101)

Naturalmente, é sempre complicado estabelecer quais necessidades deveriam ser satisfeitas pela sociedade e, portanto, quais seriam os meios para tal fim que a sociedade deveria disponibilizar a seus membros. Contudo, podemos aceitar a ideia de que os membros de uma sociedade podem chegar a um consenso sobre a razoabilidade de exigir a satisfação social de certas necessidades. Isso é o que alguns autores, por ex. John Baker (1992, p. 106), chamam de "consenso de fundo" ou background agreement. Esse consenso poderia ser alcançado democraticamente e justificaria a transformação das necessidades em direitos, embora não se trate de todas as possíveis necessidades, naturalmente, mas somente daquelas que a sociedade em questão considera básicas. 
Elisabeth S. Anderson, apresentando sua teoria da igualdade democrática e retomando a definição rawlsiana da sociedade como sistema equitativo de cooperação entre indivíduos livres e iguais, salienta a importância de garantir aos membros da comunidade política as condições que lhes permitem participar paritariamente de tal sistema. Anderson recorre ao conceito de capabilities desenvolvido por Amartya Sen. Brevemente: o termo capabilities não indica meras habilidades ou capacidades, mas se refere às condições subjetivas e objetivas que permitem aos indivíduos desempenhar certos "funcionamentos", ou seja, praticar certos atos ou alcançar certos estados. Por exemplo, para possuir certo nível de alfabetização não é suficiente que o indivíduo se esforce para aprender a ler e escrever, mas é necessário que exista uma estrutura de ensino que the possibilite tal atividade de aprendizado. A existência de uma escola pública é uma capability tanto quanto a capacidade de aprendizado de um indivíduo. Com base na teoria das capabilities, Anderson afirma: “Negativamente, as pessoas têm direito a quaisquer capabilities que sejam necessárias para permitir-lhes subtrair-se a relações sociais opressivas. Positivamente, têm direito às capabilities necessárias para funcionar (functioning) como cidadãos iguais em um Estado democrático" (ANDERSON, 1999, p. 316). Anderson define a ideia de igualdade cidadã em sentido bastante amplo, já que não a limita à esfera política. Ela identifica três níveis nos quais o indivíduo participa da vida comum em sociedade, e em cada nível o indivíduo deve ser capaz de certos atos ou 'funcionamentos' (sempre na terminologia de Amartya Sen) e, portanto, possuir certas capabilities. Os três níveis são: (1) o nível mais geral no qual deve 'funcionar' como ser humano, (2) o do sistema econômico e (3) o da vida política. No primeiro nível, deve ter acesso aos meios para garantir sua sobrevivência biológica (da nutrição ao cuidado médico), mas também às capabilities ligadas ao desenvolvimento de sua autonomia como sujeito moral. $\mathrm{O}$ segundo nível exige o acesso efetivo aos meios de produção e à educação necessária para desenvolver seus talentos, assim como a liberdade de escolher sua profissão e de fazer contratos e o reconhecimento da própria contribuição à produção de riqueza social (reconhecimento que se dá principalmente, mas não unicamente, pelo recebimento de 
salário adequado à função exercida). $\mathrm{O}$ terceiro exige as capabilities necessárias para a participação ativa na vida política da comunidade, da qual já falamos anteriormente.

Ao descrever o âmbito da sociedade civil, no qual o indivíduo vive sua vida, Anderson chama nossa atenção para o fato de que tal âmbito é muito mais amplo do que se possa pensar, já que

suas instituições compreendem as ruas e os parques públicos, lugares públicos como restaurantes, lojas, teatros, ônibus e aviões, sistemas de comunicação como rádio e TV, telefone e internet, livrarias públicas, hospitais, escolas etc. Também empresas que produzam para o mercado são parte da sociedade civil, já que vendem seus produtos para qualquer cliente e recrutam seus funcionários do público geral. (ANDERSON, 1999, p. 316 s.)

Ora, qualquer indivíduo ou grupo que seja excluído da participação de tais instituições pela falta de capabilities (ou por uma discriminação racista ou classista) é de fato relegado a um nível de cidadania de série $B$, por assim dizer.

Nesta concepção, nenhum membro da sociedade é uma ilha. Sua personalidade, inclusive suas capacidades e seus talentos, só se desenvolvem no contexto social no qual está inserido. Nada do que alcança é completamente fruto de sua ação individual, mas depende sempre do espaço de manobra que o contexto social lhe deixa. O exercício da atividade profissional, o desenvolvimento de certo estilo de vida, o cultivo dos gostos pessoais: tudo isso depende de tal contexto. Na cotidianidade é comum que as pessoas esqueçam isso e considerem como uma obviedade ou um fato natural fenômenos que na realidade dependem da existência da sociedade e do cumprimento de determinadas tarefas por parte de outros membros da sociedade. Um dos maiores êxitos da ideologia neoliberal consiste precisamente em ter ocultado esses aspectos, exaltando o mito do sujeito que é capaz de dominar plenamente sua vida sozinho e que, portanto, é responsável por tudo o que obtém nela. Ao criticar essa imagem da economia como sistema povoado por tantos Robinsons Crusoés autossuficientes, Anderson salienta sarcasticamente que os empresários da Wall 
Street não conseguiriam ganhar seus milhões se tivessem que atender pessoalmente o telefone ou, poderíamos acrescentar, limpar seus escritórios, preparar sua comida, cuidar de seus filhos, ir e vir a pé em vez de carro ou metrô etc. Deste ponto de vista, sua eficiência em realizar suas tarefas depende da eficiência de outros em realizar as próprias tarefas, por mais simples que sejam e aparentemente desligadas da atividade de ganhar dinheiro na bolsa. $\mathrm{O}$ fato de a sociedade se basear na divisão do trabalho não significa que não haja uma relação de mútua dependência entre as diferentes atividades de trabalho. Ninguém produz sozinho o que precisa para sobreviver, assim como ninguém merece ter nascido na família em que nasceu e que, pelo bem e pelo mal, irá definir suas chances de vida. Como observa Jessé Souza, criticando a ideologia economicista neoliberal, "o processo de competição social não começa na escola [...], mas já está, em grande parte pré-decidido na socialização familiar pré-escolar produzida por 'culturas de classe' distintas" (SOUZA, 2009, p. 18). ${ }^{4}$

Se formos aplicar neste contexto o princípio de justificação interpessoal introduzido por Gerald Cohen, que impõe que qualquer argumento em prol de uma política pública deve ser traduzido na forma de uma afirmação a ser feita perante qualquer membro da sociedade (COHEN, 1995, p. 348), resultaria difícil justificar políticas públicas que discriminem alguns destes membros com base na sua posição social, ou que não lhes garantam o status de igualdade enquanto membros da comunidade (por exemplo, seria difícil defender uma posição como a seguinte: "Gastaremos dois terços do orçamento para a educação no ensino público de terceiro grau, ao qual têm acesso quase exclusivamente jovens de classe média, e só um terço no ensino primário e secundário público, do qual se servem quase exclusivamente jovens de famílias de baixa renda" 5 ). O princípio do igual respeito, essencial a cada democracia, impõe que tratemos com respeito todos os cidadãos, inclusive os que desempenham as tarefas mais humildes e menos qualificadas, ou

4 Para compreender melhor estas questões recomenda-se a leitura da obra pioneira A distinção de Pierre Bourdieu (BOURDIEU 2007), sobretudo no que diz respeito ao conceito de "capital cultural".

5 Contudo, esta foi a política dos governos brasileiros por muitas décadas. 
os que não desempenham nenhuma tarefa social por falta de condições (desemprego, doença, falta de qualificação etc.).

Existem, portanto, um dever negativo e um dever positivo que a sociedade possui perante seus membros. $\mathrm{O}$ negativo é o de não discriminar, de não oprimir, de não explorar. Este dever cabe às instituições próprias da sociedade assim como a cada membro. O positivo é o de criar as condições para que os membros possam participar como sujeitos livres e iguais (no sentido acima mencionado) do sistema de cooperação socioeconômica que é a própria sociedade. A realização deste dever cabe em primeiro lugar às instituições, começando pelas instituições políticas; mas é dever de qualquer cidadão que se diga democrático apoiar qualquer medida e política pública que contribua eficazmente a tal finalidade.

\section{Referências}

ANDERSON, E. What is the Point of Equality? Ethics, v. 109, n 2, p. 287-337, 1999.

BAKER, J. “An Egalitarian Case for Basic Income”. In: VAN PARIJS, P. (Ed.). Arguing for Basic Income. Ethical Foundations for a Radical Reform. London: Verso, 1992.

BOURDIEU, P. A distinção. Crítica social do julgamento. Porto Alegre; São Paulo: Editora Zouk; EDUSP, 2007.

COHEN, G. A. Incentives, Inequality, and Community. In: DARWALL, S. (Ed.). Equal Freedom. Ann Harbour: University of Michigan Press, 1995, 331-397.

FERNANDES, F. A integração do negro na sociedade de classes. São Paulo: Dominus : Ed. Univ. S. Paulo, 1965.

GALEOTTI, A. E. La politica del rispetto. I fondamenti etici della democrazia. Roma \& Bari: Laterza, 2010.

HABERMAS, J. A Inclusão do Outro. São Paulo: Edições Loyola, 2002. 
HARRIS, D. Justifying State Welfare. Oxford: Blackwell, 1987.

VON HAYEK, F. Direito, Legislação e Liberdade. Vol. III. São Paulo: Visão, 1985.

LEÃO REGO, W; PINZANI, A. Vozes do Bolsa Família. Autonomia, dinheiro e cidadania. São Paulo: Editora da UNESP, 2013.

MARGALIT, A. The Decent Society. Cambridge: Harvard University Press, 1996.

MARSHALL, T. H. Cidadania, classe social e status. Rio de Janeiro: Jorge Zahar, 1967.

SMITH, A. A riqueza das nações. Investigação sobre sua natureza e suas causas. 2 voll. São Paulo: Nova Cultural, 1996.

SOUZA, J. (Org.). A ralé brasileira. Quem é e como vive. Belo Horizonte: Editora da UFMG, 2009.

Recebido: 16/10/2015

Received: 10/16/2015

Aprovado: 14/01/2016

Approved: 01/14/2016 